\title{
micromachines
}

ISSN 2072-666X

www.mdpi.com/journal/micromachines

Article

\section{The Migration of Cancer Cells in Gradually Varying Chemical Gradients and Mechanical Constraints}

\author{
Smitha M. N. Rao ${ }^{\dagger} *$, Uday Tata ${ }^{\dagger}$, Victor K. Lin and Jung-Chih Chiao \\ Department of Electrical Engineering, University of Texas at Arlington, NH 538, Box 19016, \\ Arlington, TX 76019, USA; E-Mails: tata.uday@mavs.uta.edu (U.T.); victor.lin@uta.edu (V.K.L.); \\ jcchiao@uta.edu (J.-C.C.)
}

$\dagger$ These authors contributed equally to this work.

* Author to whom correspondence should be addressed; E-Mail: smitha@uta.edu;

Tel.: +1-817-272-2306.

Received: 1 December 2013; in revised form: 31 December 2013 / Accepted: 10 January 2014 /

Published: 22 January 2014

\begin{abstract}
We report a novel approach to study cell migration under physical stresses by utilizing established growth factor chemotaxis. This was achieved by studying cell migration in response to epidermal growth factor (EGF) chemoattraction in a gradually tapered space, imposing mechanical stresses. The device consisted of two 5-mm-diameter chambers connected by ten $600 \mu \mathrm{m}$-long and $10 \mu \mathrm{m}$-high tapered microchannels. The taper region gradually changes the width of the channel. The channels tapered from $20 \mu \mathrm{m}$ to $5 \mu \mathrm{m}$ over a transition length of $50 \mu \mathrm{m}$ at a distance of $250 \mu \mathrm{m}$ from one of the chambers. The chemoattractant drove cell migration into the narrow confines of the tapered channels, while the mechanical gradient clearly altered the migration of cells. Cells traversing the channels from the wider to narrow-end and vice versa were observed using time-lapsed imaging. Our results indicated that the impact of physical stress on cell migration patterns may be cell type specific.
\end{abstract}

Keywords: microfluidics; tapered channels; chemotaxis; cell migration; cancer metastasis

\section{Introduction}

Cancer cells at the primary tumor site(s) acquire the ability to migrate to a distant site to form a secondary tumor characterize cancer metastasis. Metastasis is a critical step in the spreading and 
progression of cancer. It is an indication of a poor prognosis for certain cancers, including breast cancers and prostate carcinoma [1]. Molecular mechanisms underlying the cellular events of cancer metastasis are not well understood. These cellular events may include metastatic cell detachment, infiltration and migration from the primary tumor mass. It is conceivable that the alteration of gene expression occurs in the metastatic cells to accommodate specific enzymatic digestion of embedding extra-cellular matrix (ECM), to gain the ability for extra- and intra-vasation, through the blood and lymphatic vessel walls. These cellular responses may have resulted from biochemical stimulation and/or mechanical force-induced signal transduction. It has been reported that the metastasis of breast cancer, is mediated by the stimulation of chemokines and transforming growth factor beta (TGF $\beta$ ) [2-10]. The upregulation of a variety of chemokines and other growth factors, such as epidermal growth factor (EGF) [11] and vascular endothelial growth factor (VEGF), has also been shown to be associated with cancer metastasis [12]. Mechano-transduction mechanisms have also been postulated, which state that cells are capable of converting mechanical signals to a series of biochemical, molecular and cellular events [4,11-17].

Microfluidics has rapidly developed in recent years and become one of the well-recognized technologies in analytical bio-medical sciences, including molecular separation, biochemical assays, drug screening, electro-chromatography and invasion assays, to name a few [4,18-44], owing to its advantages, such as the small amounts of reagents/liquid required, the ease of optical observation, biochemical probing, the quick prototyping of fluidic configuration and the possibility of single cell examination. Microfluidics has been used to investigate the molecular mechanisms of cell migration and metastasis [43,45-47] and recently utilized as a powerful platform to study single cell chemotactic migration. We have previously reported the design of a microfluidic device by which we provided evidence of: (1) the establishment and maintenance of a chemical gradient in the device; and (2) directional cell chemotaxis toward growth factors $[48,49]$. With the demonstrated microfluidic device as a tool, further understanding of the fundamental signals regulating migration at the cellular level is essential for the development of therapeutic approaches. Individual cells rely on the intrinsic redistribution of cellular molecules/components to migrate in response to gradients of extrinsic signals [50,51]. These signals include chemical, spatial physical stresses or electromagnetic stimulations [50-54]. The chemical signal transducing mechanisms for regulating cell migration have been established due to its importance in cancer progression and metastasis [52-57]. However, the effects of physical stress signaling in cell migration patterns still remain largely unclear. The most recent study by Mak et al. [58] took into consideration the effect of physical spatial gradients. Their study provided direct evidence that physical stresses could lead to changes in migration patterns of MCF10A, a normal breast cell line, and MDAMB231, a malignant breast cancer cell line. In the present study, we have designed a microfluidic platform to impose mechanical stresses on cells chemotactically driven into the microchannels. A biochemical gradient attracting cancerous or noncancerous cells towards a more stringent bio-mechanical stress condition imposed by tapered microchannels provides both stimuli at the same time on individual cells in situ. Our hypothesis is that three-dimensional interaction among cells in the tapered channels causes cellular stresses that may alter the cell migration pattern. It may be used as a model to understand the apparent enhancement of the cellular migration potential in cancer cells compared to that of normal cells. 
The transition length of the microfluidic device in this study represents a region of gradually changing physical and chemical environments. The cells that migrate into this region are chemically stimulated and simultaneously subjected to very stringent mechanical stresses. The chemical gradients create a microenvironment that impacts the chemotaxis of the cell. The narrower channels amplify the physical stresses and impact the cell structure, causing significant changes in the migration behavior of the cells. This is clearly demonstrated by comparing with migration patterns observed in a uniform channel study, previously reported in [48,49]. In brief, the migration of cells in microfluidic devices with uniform channels $(20 \mu \mathrm{m}$-wide, $10 \mu \mathrm{m}$-high) showed a higher migration of cancerous cells compared to the control. The migration was also concentration dependent. For example, the migration of PC-3 cells in response to $100 \mathrm{ng} / \mathrm{mL}$ of EGF was much higher than that for $30 \mathrm{ng} / \mathrm{mL}$. The cells migrated across the entire length of the channel, entered the open chamber on the other end and continued to proliferate.

\section{Experiments}

\subsection{Device Design and Fabrication}

The microfluidic device consisted of two open chambers of a $5 \mathrm{~mm}$ diameter each to hold cells with $70 \mu \mathrm{L}$ of media or designated chemoattractants, depending on the experiment designs. These two chambers were connected by ten micro-channels of $10 \mu \mathrm{m}$ in height and $600 \mu \mathrm{m}$ in length as shown in Figure 1.

Figure 1. The design of the microfluidic device: The microfluidic device consists of two chambers connected with ten $600 \mu \mathrm{m}$-long and $10 \mu \mathrm{m}$-high microchannels. The channels taper from $20 \mu \mathrm{m}$ to $5 \mu \mathrm{m}$ over a transition length of $50 \mu \mathrm{m}$ towards the center of the channels.

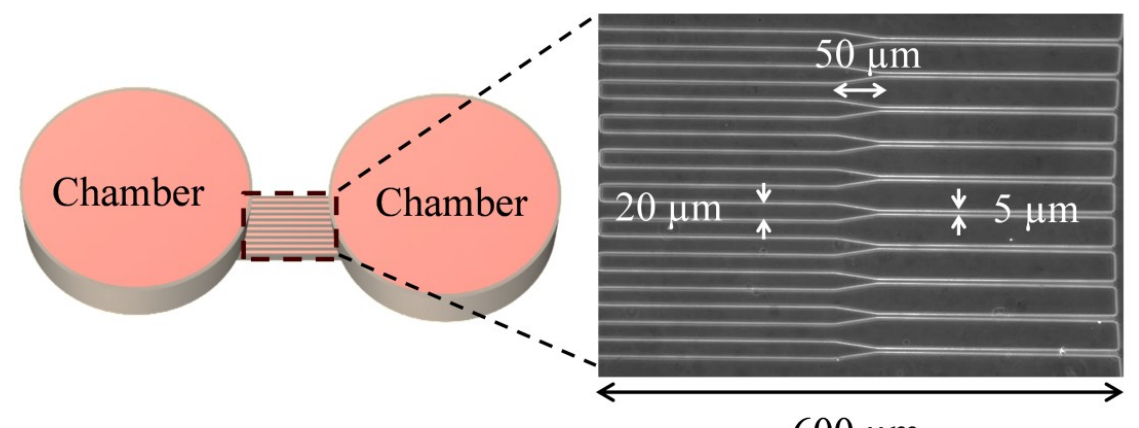

$600 \mu \mathrm{m}$

The spacing between adjacent channels was $20 \mu \mathrm{m}$. The width of the channels was chosen due to the fact that the cells tested were in the range of $20-50 \mu \mathrm{m}$ in diameter. Thus, a channel width of $5 \mu \mathrm{m}$ provides an extremely stringent condition for cells to migrate. Furthermore, our device provides a polarized micro-environment for cell studies. The microfluidic devices were fabricated with PDMS (polydimethylsiloxane) using soft lithography processes. In brief, a mold was created on a silicon wafer using the negative tone photoresist SU-8-2010 (Microchem, Newton, MA, USA). The mold was cured at $150{ }^{\circ} \mathrm{C}$ for $40 \mathrm{~min}$. The PDMS (Sylgard 184, Dow Corning, Midland, MI, USA) was polymerized by curing a mixture of 10 parts of PDMS base to 1 part of cross-linker (by weight). To ensure a consistent height of all the devices fabricated, a controlled quantity of the polymer was 
always used. The mixture was allowed to set on the SU-8 mold and degassed in a vacuum chamber. The polymer was then cured at $90{ }^{\circ} \mathrm{C}$ for $90 \mathrm{~min}$. The cured device was peeled from the mold and diced. The PDMS dies were then individually cleaned, sterilized and mounted on standard tissue culture dishes (60 mm, treated polystyrene, Corning Inc., Lowell, MA, USA) by applying pressure on the PDMS dies with the channel side onto the growth surface of the substratum to form the microfluidic device. The PDMS devices can form very strong temporary bonds with other smooth clean surfaces, such as tissue culture plates, by simple electrostatic interaction between the PDMS and the tissue culture substrate. The absence of air pockets between the device and the substrate indicated a good bond [59]. Since the experiment was carried out without any pressure driven flow, the temporary bond between the PDMS and the culture plate was enough. The PDMS is hydrophobic, while the substrate is hydrophilic, making priming and cell seeding possible. In addition, the use of the tissue culture substratum ensures that cell culture conditions remain unaltered. The device was primed with growth media in preparation for the designated experiments. Priming was carried out by first filling one of the chambers of the microfluidic device with culture media. Vacuum suction was then employed to each device to draw the media through the ten channels. The device was then observed under a microscope for leaks before being filled with media and placed in an incubator for $24 \mathrm{~h}$. Priming the device before the experiment eliminated trapped air bubbles and helped in identifying any potential leak. In addition, we also checked each device carefully for channel damage and contamination. For the ease of imaging and analysis, we always used the convention of placing the cell seeding side towards the left with the chemoattractant side on the right within the field-of-view.

\subsection{Cell Migration}

Experiments were designed to study the chemotaxis of prostate cells (both normal and cancerous) to the chemo-mechano stress induced by epidermal growth factor (EGF) in the tapered channels. The chemical gradient generated by the diffusion of $75 \mathrm{ng} / \mathrm{mL}$ EGF within the tapering channels of the microfluidic device stimulated the migration. The concentration of EGF was chosen based on our previous study utilizing uniform channels, which indicated that $75 \mathrm{ng} / \mathrm{mL}$ of EGF enhanced the migration of prostate cancer cells (data not shown) [60].

The microfluidic devices were sterilized with $70 \%$ ethanol and mounted on a standard tissue culture dish with the channel side down. The two chambers and interconnecting microchannels were primed by growth media, as described earlier. PC-3 cells, a human prostate cancer cell line [61], and PNT1A, an immortalized normal human prostate epithelium preparation [62], were used to characterize cellular responses to stress signals. Both cell lines were grown in Roswell Park Memorial Institute medium 1640 or RPMI 1640 supplemented with 5\% fetal bovine serum (FBS), $100 \mathrm{U} / \mathrm{mL}$ penicillin and 100 $\mu \mathrm{g} / \mathrm{mL}$ streptomycin maintained under $5 \% \mathrm{CO}_{2}$ atmosphere at $37{ }^{\circ} \mathrm{C}$. Cells at a density of $72 \times 10^{3}$ in the growth media were seeded into each seeding chamber, conventionally on the left in the field-ofview, while $70 \mu \mathrm{L}$ of growth media without cells was added to the chemoattractant chamber. After a 24-h incubation, allowing the cells to anchor, the media with EGF $(75 \mathrm{ng} / \mathrm{mL})$ were added to the appropriate chemoattractant chambers. In order to minimize the evaporation of the media in the devices, sterilized PBS was added around the microfluidic device. Real-time cell migration was recorded using time-lapse microscopy (Ti Eclipse, Nikon, Meville, NY, USA). The microscope was 
equipped with a Bold Line Cage Incubator (Okolab, Italy) with $\mathrm{CO}_{2}$ supply. Images of the cells within the channels were captured at $100 \times$ to show the relative location along the microchannels at 2-min intervals for a period of $72 \mathrm{~h}$. The compiled images were used to measure the movement of the cells in the channels.

PC-3 cells were able to migrate across the tapered microchannels in response to the EGF gradient. They were thus exposed to a gradually stringent mechano-stress condition. These cells continued to migrate across the narrow $5 \mu \mathrm{m}$-wide channels. Similar observations were made when PNT1A cells were subjected to identical experiment conditions. These results clearly demonstrated that cells may actively migrate into an extremely narrow space as part of the chemotactic response, mimicking the process of intravasation during metastasis [63].

Figure 2. Time lapse microscopic images of migration behaviors for (a) PC-3 cells and (b) PNT1A cells, when seeded in the chamber at the wider $(20 \mu \mathrm{m})$ end of the channel with an attractant (epidermal growth factor (EGF) at $75 \mathrm{ng} / \mathrm{mL}$ ) added in the chamber near the narrow end $(5 \mu \mathrm{m})$. The images were zoomed in to the tapered channel area. In the case of PC-3, the cells re-entered the channels, as indicated by the arrows. In the case of PNT1A, the cells migrated completely across the channels into the chamber.

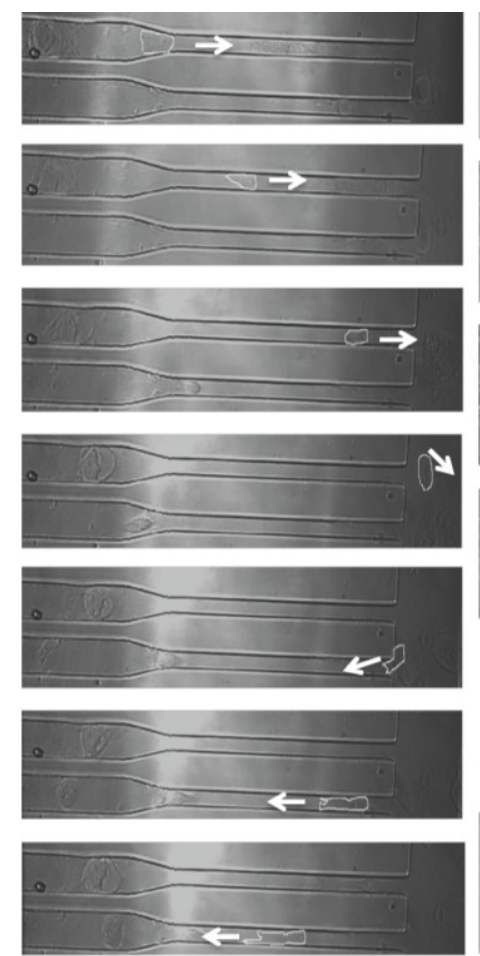

(a)


(b)

Interestingly, when PC-3 cells chemotaxied through the entire length of the channel and exited from the narrower end, some of the cells were observed to immediately re-enter the same or the very next channel, which was also narrow (Please refer to Video 1 in the Supplementary Material in the Electronic Supporting Information). The cells that re-entered were then seen to migrate in the opposite direction, i.e., against the EGF gradient across the entire length of the narrow channels, as shown in Figure 2a. For PC-3 cells, this re-entering phenomena occurred more frequently (10 out of 14 occurrences), as illustrated in Figure 3. PNT1A cells were observed to have only three out of 
a total of 44 occurrences in which the cells re-entered the narrow channels. The cells are depicted in Figure $2 \mathrm{~b}$ and Video 2 (Please refer to Video 2 in the Supplementary Material in the Electronic Supporting Information), in which all cells were moving towards the right. The frequency for PC-3 cells immediately re-entering the channels (78\%) was much higher than that of PNT1A cells (7\%). These observations suggest that the cells continue to seek similar microenvironments, as evidenced by their immediately re-entering of the narrow microchannels. This phenomenon appears to be cell type-specific, since the responses between PC-3 cells and PNT1A cells were different, as shown in Figure 3. It is worth noting that in the uniform ( $20 \mu \mathrm{m}$-wide from chamber to chamber $)$ microchannels with am EGF gradient from 0 to $75 \mathrm{ng} / \mathrm{mL}$, PC-3 migrated towards a higher EGF concentration (data not shown), as we have previously reported $[48,49]$. It was also observed that almost all the cells that migrated through the microchannels with a uniform width remained and proliferated in the chemoattractant chambers. These cells were not observed to re-enter the channels or migrate back towards the cell seeding chamber.

Figure 3. The comparison of the migration patterns between PC-3 and PNT1A cells when cells were seeded on the wider end of the tapered channels. The arrows and numbers indicate the direction of cell migration and the number of cells under migration. PC-3 re-entry is at a much higher rate than that for PNT1A.
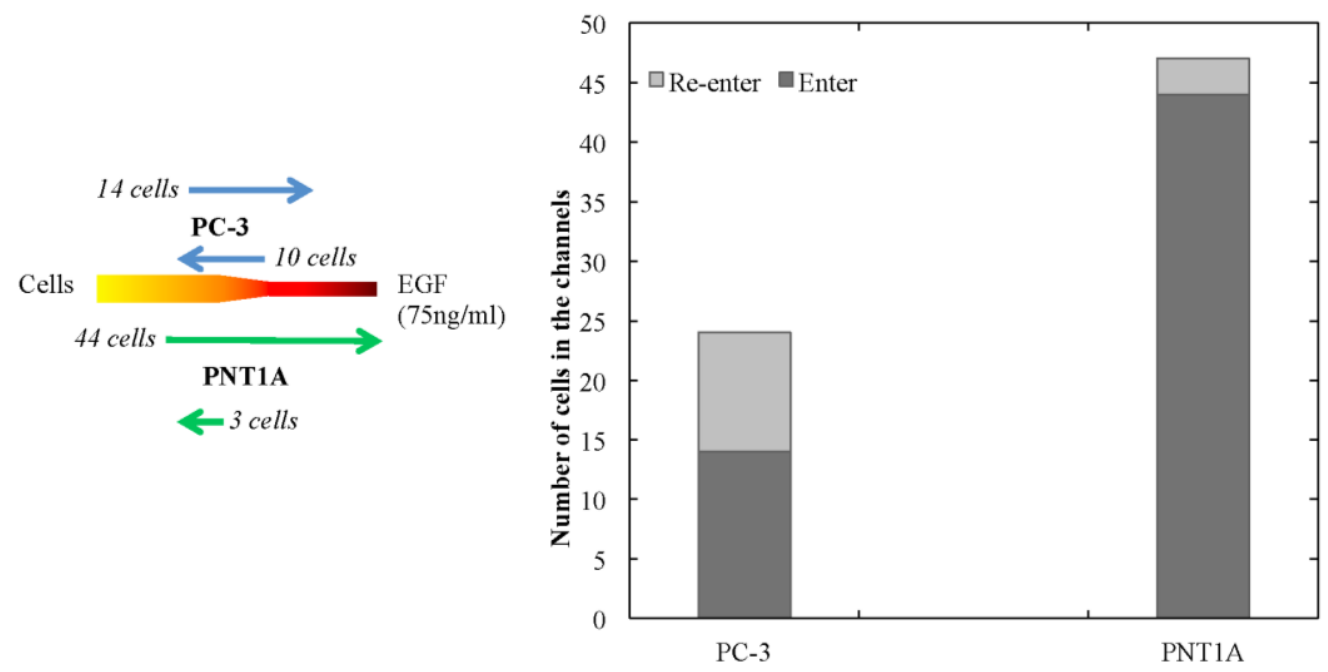

The migration of cells from the narrow to the wider end of the channels was also assessed under identical conditions, as illustrated in Figure $4 \mathrm{a}$ and Video 3 (Please refer to Video 3 in the Supplementary Material). The EGF gradient promoted the migration of cells across the $5 \mu \mathrm{m}$ narrow microchannels from the left side moving to the right in Figure 4. However, upon reaching the region of channel width transition, the cells continued to move into the wider $20-\mu \mathrm{m}$ channels towards the attractant well (as observed in 12 events). In seven events, the cells returned to the narrow channels, such as in the case shown in Figure 4a. In an identical experimental setting with PNT1A cells, the cells were observed to prefer the wider region of the channel, with only 1 out of 36 events showing that the cell returned to the narrow microchannels, as shown in Figure $4 \mathrm{~b}$ and Video 4 (Please refer to Video 4 in the Supplementary Material). These results suggest that PC-3 cells chemotaxied and preferred the $5-\mu \mathrm{m}$ microchannels irrespective of whether they reached the narrow channel from a wider channel or 
entered the narrow channel directly; while PNT1A cells seem to prefer the wider space. Figure 5 compares the numbers of re-entering events when the cells were seeded in the chamber near the narrow channels with cells migrating toward the chemoattractant gradient from the right side.

Figure 4. Time-lapsed microscopic images of migration behaviors for (a) PC-3 cells and (b) PNT1A cells, when seeded on the narrow end with EGF $(75 \mathrm{ng} / \mathrm{mL})$ in the chamber on the wider end. As indicated by the arrows, PC-3 cells re-entered the channels, while PNT1A cells continued to migrate across the entire length of the channel to the other side.

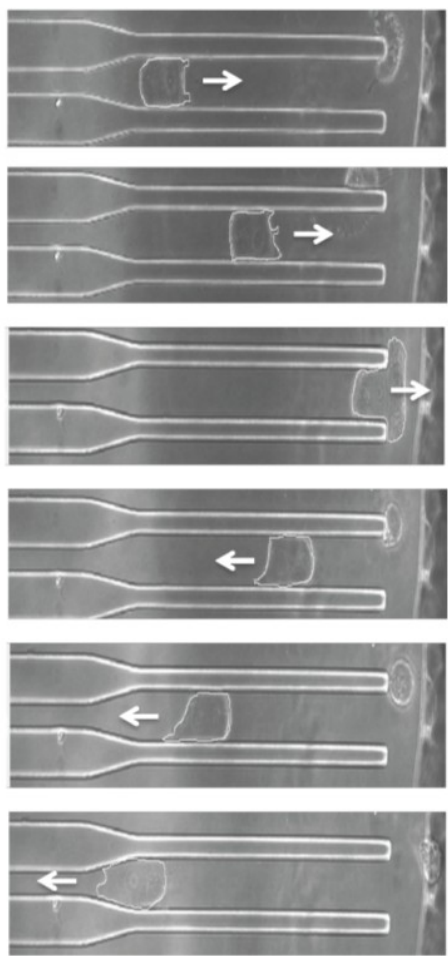

(a)
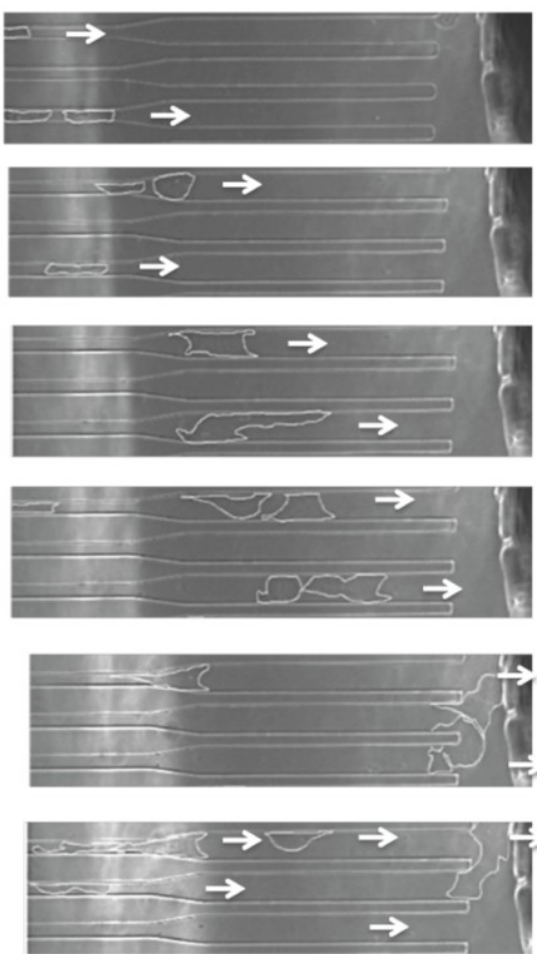

(b)

Figure 5. Comparison of the migration patterns between PC-3 and PNT1A when cells were seeded on the narrower end of the tapered channels. The arrows and numbers indicate the direction of cell migration and the number of cells. PC-3 cell re-entry is at a much higher rate than that for PNT1A.

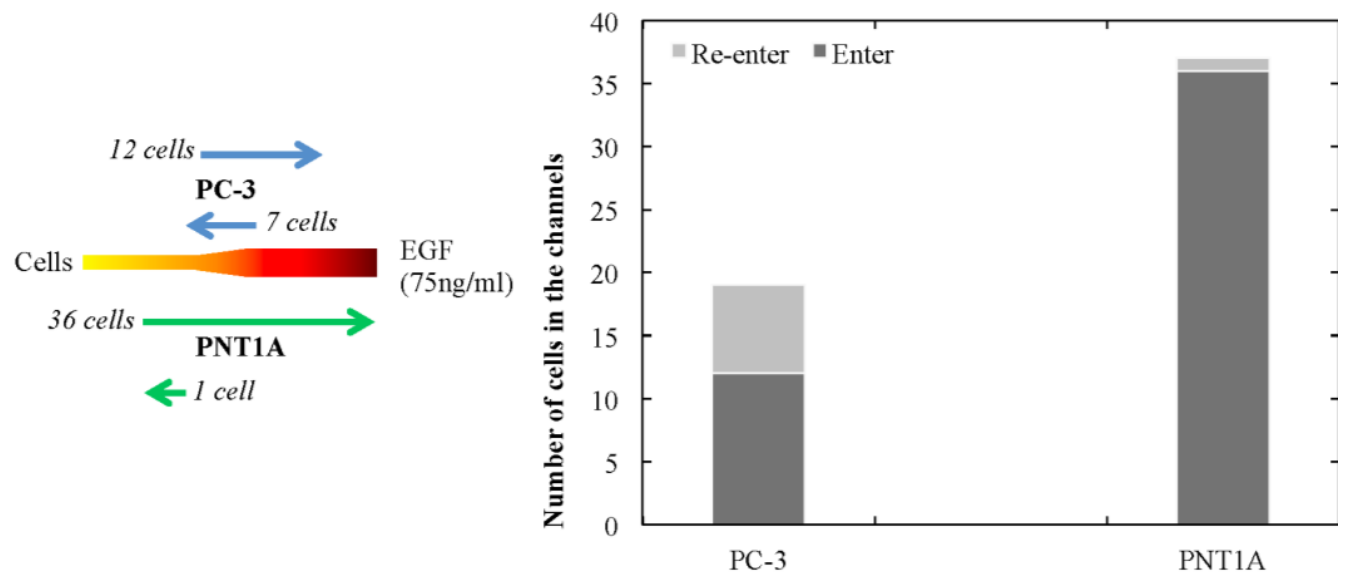


Our devices also permit us to obtain kinetic data for cells in the process of chemotaxis under mechano-stress stimulation. The chemotactic responses of PC-3 and PNT1A cells in the tapered $5 \mu \mathrm{m}$ narrow microchannels were assessed. Each cell was tracked to find the time required for migration across the $250 \mu \mathrm{m}$ length of the narrow channel in order to calculate its migration speed. In the experimental configuration, cells were added near the wider region of the channel and the attractant was added to the other chamber. The results indicated that the average chemotactic migration speed of PC-3 was $60 \mu \mathrm{m} / \mathrm{h}(n=14)$, whereas it was $19 \mu \mathrm{m} / \mathrm{h}(n=44)$ for PNT1A. The result is shown in Figure 6. The outcomes provided by Mak et al. [58] indicated that physical gradients led to distinctive migration patterns among normal and malignant cells. However, our results indicated that chemical gradients generated by EGF in the channels led to the migration of the normal, as well as malignant cells into the tapered channels. The difference was observed when the cells reached the chamber after exiting the tapered channels.

Figure 6. The speed of migration for PC-3 and PNT1A cells. The average speed of migration $(\mu \mathrm{m} / \mathrm{h})$ is calculated by the time required for the cells that migrated across the entire length of the $5-\mu \mathrm{m}$ narrow channel. * indicates a statistical significance of $p<0.05$.

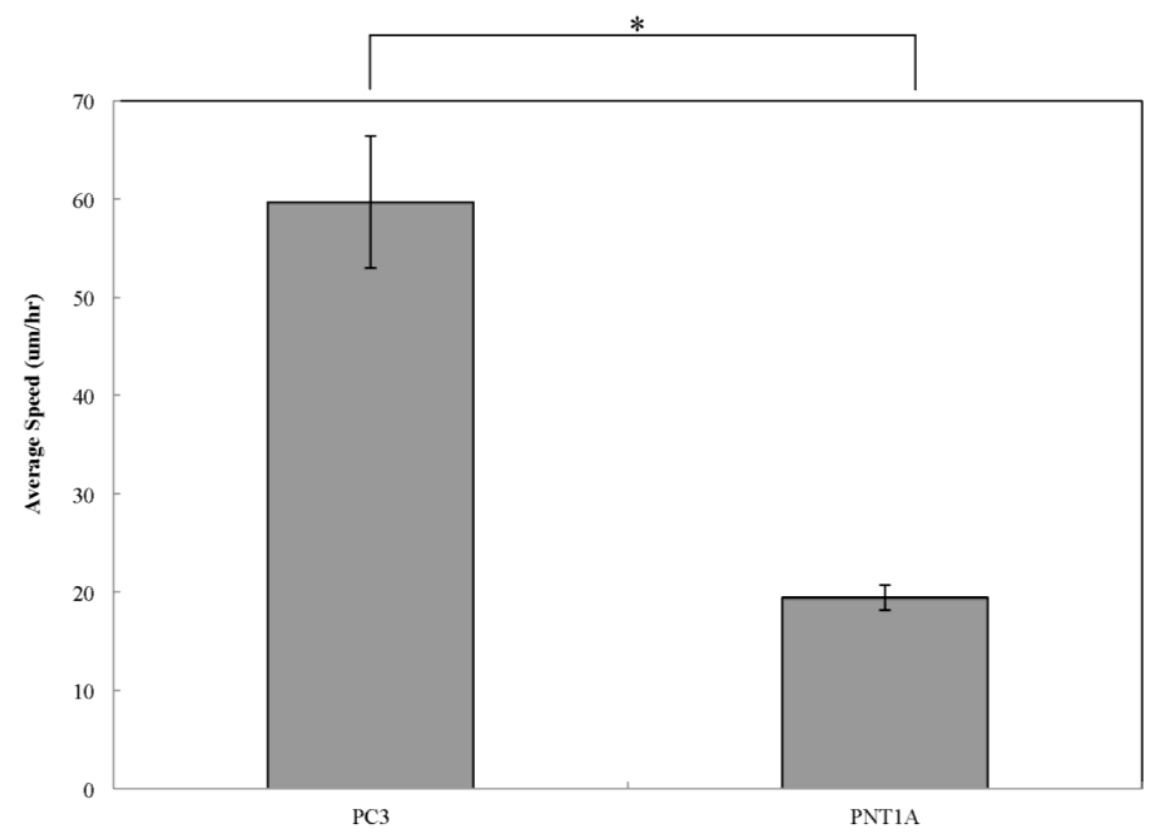

The tapered channel design was aimed at studying the hypothesis that chemo-mechano-stresses applied to the cells may lead to distinctive migration patterns among different cells. The differences seen between PNT1A and PC-3 cells may provide insights into the understanding of molecular and cellular mechanisms in metastasis. In our previous studies $[48,49]$, the channels in the microfluidic devices had a uniform width throughout the length of the channel. The main observation with respect to cell migration and the cell line were similar. Cancerous cell lines demonstrated an apparent increase in migration compared to the control cells. However, the migration of the cells observed in this case did not involve a preferential re-entering into the channels, as exhibited by the cancerous line in the tapered channels. Thus, we concur that metastasis apparently involves cellular motility. Although the molecular mechanism underlying the cancer cell metastasis is still largely unclear, it is generally 
recognized that cellular sensing of and responses to chemical gradients are crucial steps in the process. This leads to dynamic and polarized receptor re-distribution on the cell body. Subsequent steps may include a cascade of signal activation, polymerization of actin filaments and the formation of pseudopodia and result in the physical movement of the cell. A mammalian adherent cell may be approximately $20 \mu \mathrm{m}$ in diameter and approximately $2000 \mu \mathrm{m}^{3}$ in volume [64]. Therefore, the physical condition of a cell moving along a narrow channel with an area of a cross-section of $5 \mu \mathrm{m} \times 10 \mu \mathrm{m}$ could further enhance the polarization and re-distribution of receptors and the cellular events, providing insight into the mechanisms involved in cell migration leading to metastasis.

We have also presented evidence to demonstrate that this microfluidic device allows us to investigate cellular events and their underlying molecular mechanisms for cell migration in the processes of chemotaxis and mechano-stress stimulations. The migratory behaviors of different cell types in response to the combination of physical stress and chemical gradient were studied. The imposition of a chemical gradient driving the cells into a mechanical stress environment of the tapering channel resulted in cell migration behavior changes, as evidenced and clearly demonstrated by the immediate re-entering into the stringent narrow $(5 \mu \mathrm{m})$ channels in the case of PC-3. The cells that re-entered were observed to return and to travel the entire length of the narrow channel in the opposite direction against the chemical gradient of EGF. We also demonstrated that that PC-3 cells, a prostate cancer cell line, exhibited a significantly higher frequency of re-entering compared to PNT1A cells (a normal prostate epithelial cell preparation).

Two of the unique features in our microfluidic devices are that the cells can be observed in real time and in a time-lapsed fashion to understand the dynamic behaviors of cells under migration and the ability to retrieve the cells of interest for further molecular analysis while the cells are in the process of migration. Thus, future work will be to conduct immuno-cytochemical analysis on the cells under migration in the different experiment configurations shown in this paper in order to verify the chemotactically-driven, mechanical stress-induced signaling molecule re-distribution and polarization at the protein expression level in cells. The main limitations of the experimental set-up that we will be addressing in the future are with regards to the device priming and data collection. Currently, arrays of microfluidic devices are cleaned and sterilized, while priming is still done one device at a time. In the future, methods to simultaneously prime multiple devices will be explored. In addition, for data collection, the images taken using time-lapse are automated, but the determination of cell migration is carried out manually. We are actively investigating ways to automate the process.

\section{Conclusions}

Previous works that used a highly confining environment to study cell migration and adhesion have primarily involved straight and uniform microchannels. Rao et al. [48] and Tata et al. [49] have demonstrated a non-flow-based microfluidic arrayed device with controlled chemical gradients for studying prostate cancer chemotaxis with EGF, in which most of the cells migrated across the channels into the attractant chamber. The advantages of such devices include the use of smaller amounts of reagents, time-lapsed observation of cell migration and quantitative assessment of cell migration. Mak et al. [58] demonstrated that a physical gradient with increasing mechano-stress device produced a difference in the migratory behaviors of breast cancer cells, because of the tapered channels. 
However, the data from these studies did not address the combined effects of physical and chemical gradients, which is the actual signaling scenario for cancer metastasis. This paper presents a unique aspect of cell migration behaviors, addressing both physical and chemical stimuli. The results clearly demonstrated that the chemical and physical constraints play a role in altering cellular migration characteristics. We have observed the behavioral differences in the migration responses of different cell types (cancerous vs. non-cancerous). In the future, the device will be used as a label-free method of quantitatively characterizing signaling feedback on the single cell level by analyzing the responses of cells and the migration transition dynamics.

\section{Acknowledgments}

We would like to thank TxMRC (Texas Medical Research Collaborative) and the National Institute of Health (NIH) grant R15CA133623 from the National Cancer Institute for their financial support. We also appreciate Annuziato and Greene for their support of our research.

\section{Conflicts of Interest}

The authors declare that there is no conflict of interest.

\section{Reference}

1. Hanahan, D.; Weinberg, R.A. Hallmarks of cancer: The next generation. Cell 2011, 144, 646-674.

2. Transforming Growth Factor- $\beta$ in Cancer Therapy. In Cancer Treatment and Therapy; Jakowlew, S.B., Ed., Humana Press:Totowa, NJ, USA, 2008; Volume II.

3. Kang, Y.; He, W.; Tulley, S.; Gupta, G.P.; Serganova, I.; Chen, C.R.; Manova-Todorova, K.; Blasberg, R.; Gerald, W.L.; Massague, J. Breast cancer bone metastasis mediated by the smad tumor suppressor pathway. Proc. Natl. Acad. Sci. USA 2005, 102, 13909-13914.

4. Polacheck, W.J.; Li, R.; Uzel, S.G.M.; Kamm, R.D. Microfluidic platforms for mechanobiology. Lab Chip 2013, 13, 2252-2267.

5. Seton-Rogers, E.S.; Lu, Y.; Hines, M.L.; Koundinya, M.; LaBaer, J.; Muthuswamy, K.S.; Brugge, S.J. Cooperation of the ErbB2 receptor and transforming growth factor beta in induction of migration and invasion in mammary epithelial cells. Proc. Natl. Acad. Sci. USA 2004, 101, 1257-1262.

6. Xie, L.; Law, K.B.; Chytil, M.A.; Brown, A.K.; Aakre, E.M.; Moses, L.H. Activation of the Erk pathway is required for TGF- $\beta 1$-induced EMT in vitro. Neoplasia 2004, 6, 603-610.

7. Serganova, I.; Moroz, E.; Vider, J.; Gogiberidze, G.; Moroz, M.; Pillarsetty, N.; Doubrovin, M.; Minn, A.; Thaler, H.T.; Massague, J.; et al. Multimodality imaging of TGF $\beta$ signaling in breast cancer metastases. FASEB J. 2009, 23, 2662-2672.

8. Kaminska, B.; Wesolowska, A.; Danilkiewicz, M. TGF Beta signalling and its role in tumour pathogenesis. Acta Biochim. Pol. 2005, 52, 329-337.

9. Kanzaki, T.; Shiina, R.; Saito, Y.; Morisaki, H.O.A.N. Role of latent TGF- $\beta 1$ binding protein in vascular remodeling. Biochem. Biophys. Res. Commun. 1998, 246, 26-30. 
10. Wikström, P.; Stattin, P.; Franck-Lissbrant, I.; Anders Bergh, J.-E.D. Transforming growth factor $\beta 1$ is associated with angiogenesis, metastasis, and poor clinical outcome in prostate cancer. Prostate 1998, 37, 19-29.

11. Rajan, R.; Vanderslice, R.; Kapur, S.; Lynch, J.; Thompson, R.; Djakiew, D. Epidermal growth factor (EGF) promotes chemomigration of a human prostate tumor cell line, and EGF immunoreactive proteins are present at sites of metastasis in the stroma of lymph nodes and medullary bone. Prostate 1996, 28, 1-9.

12. Wang, J.H.; Li, B. Mechanics rules cell biology. Sports Med. Arthrosc. Rehabil. Ther. Technol. 2010, 2, doi:10.1186/1758-2555-2-16.

13. Ingber, D.E. Cellular mechanotransduction: Putting all the pieces together again. FASEB J. 2006, 20, 811-827.

14. Chambers, A.F.; Groom, A.C.; MacDonald, I.C. Dissemination and growth of cancer cells in metastatic sites. Nat. Rev. Cancer 2002, 2, 563-572.

15. Dieterich, P.; Klages, R.; Preuss, R.; Schwab, A. Anomalous dynamics of cell migration. Proc. Natl. Acad. Sci. USA 2008, 105, 459-463.

16. Liu, B.; Kim, T.J.; Wang, Y. Live cell imaging of mechanotransduction. J. R. Soc. Interf. 2010, 7, S365-S375.

17. Orr, A.W.; Helmke, B.P.; Blackman, B.R.; Schwartz, M.A. Mechanisms of mechanotransduction. Dev. Cell 2006, 10, 11-20.

18. Bio-MEMS Technologies and Applications, 1st ed.; Wang, W., Soper, S.A., Eds.; CRC Press: Boca Raton, FL, USA, 2006.

19. Microfluidics for Biological Applications; Tian, W., Finehout, E., Eds.; Springer: New York, NY, USA, 2008.

20. Abhyankar, V.V.; Toepke, M.W.; Cortesio, C.L.; Lokuta, M.A.; Huttenlocher, A.; Beebe, D.J. A platform for assessing chemotactic migration within a spatiotemporally defined 3D microenvironment. Lab Chip 2008, 8, 1507-1515.

21. Campbell, C.J.; Grzybowski, B.A. Microfluidic mixers: From microfabricated to self-assembling devices. Philos. Transact. A Math. Phys. Eng. Sci. 2004, 362, 1069-1086.

22. Cha, J.; Kim, J.; Ryu, S.-Y.; Park, J.; Jeong, Y.; Park, S.; Park, S.; Kim, H.C.; Chun, K. A highly efficient 3D micromixer using soft PDMS bonding. J. Micromech. Microeng. 2006, 16, 1778-1782.

23. Chang, J.K.; Bang, H.; Park, S.J.; Chung, S.; Han, C.; Chung, D.C. Fabrication of the PDMS Microchip for Serially Diluting Sample with Buffer. In Microsystem Technologies; Springer-Verlag: Berlin, Germany, 2003; Volume 9, pp. 555-558.

24. Diao, J.; Young, L.; Kim, S.; Fogarty, E.A.; Heilman, S.M.; Zhou, P.; Shuler, M.L.; Wu, M.; DeLisa, M.P. A Three-channel microfluidic device for generating static linear gradients and its application to the quantitative analysis of bacterial chemotaxis. Lab Chip 2006, 6, 381-388.

25. Duffy, D.C.; McDonald, J.C.; Schueller, O.J.A.; Whitesides, G.M. Rapid prototyping of microfluidic systems in poly(dimethylsiloxane). Anal. Chem. 1998, 70, 4974-4984.

26. Ghitun, M.; Bonneil, E.; Fortier, M.; Yin, H.; Killeen, K.; Thibault, P. Integrated microfluidic devices with enhanced separation performance: Application to phosphoproteome analyses of differentiated cell model systems. J. Seper. Sci. 2006, 29, 1539-1549. 
27. Irimia, D.; Geba, D.A.; Toner, M. Universal microfluidic gradient generator. Anal. Chem. 2006, $78,3472-3477$.

28. Jeon, N.L.; Dertinger, S.K.W.; Chiu, D.T.; Choi, I.S.; Stroock, A.D.; Whitesides, G.M. Generation of solution and surface gradients using microfluidic systems. Langmuir 2000, 16, 8311-8316.

29. Jiang, X.; Bruzewicz, D.A.; Wong, A.P.; Piel, M.; Whitesides, G.M. Directing cell migration with asymmetric micropatterns. Proc. Natl. Acad. Sci. USA 2005, 102, 975-978.

30. Leclerc, E.; Sakai, Y.; Fujii, T. A Multi-Layer PDMS Microfluidic Device for Tissue Engineering Applications. In Proceedings of the IEEE the 16th Annual International Conference on Micro Electro Mechanical Systems, Kyoto, Japan, 23 January 2003; pp. 415-418.

31. Li, J.; LeRiche, T.; Tremblay, T.-L.; Wang, C.; Bonneil, E.; Harrison, D.J.; Thibault, P. Application of microfluidic devices to proteomics research: Identification of trace-level protein digests and affinity capture of target peptides. Mol. Cell. Proteomics 2002, 1, 157-168.

32. Martin, R.S.; Root, P.D.; Spence, D.M. Microfluidic technologies as platforms for performing quantitative cellular analyses in an in vitro environment. Analyst 2006, 131, 1197-1206.

33. McDonald, J.C.; Duffy, D.C.; Anderson, J.R.; Chiu, D.T.; Wu, H.; Schueller, O.J.; Whitesides, G.M. Fabrication of microfluidic systems in poly(Dimethylsiloxane). Electrophoresis 2000, 21, 27-40.

34. McDonald, J.C.; Whitesides, G.M. Poly(Dimethylsiloxane) as a Material for fabricating microfluidic devices. Acc. Chem. Res. 2002, 35, 491-499.

35. Nie, F.; Kobayashi, J.; Yamada, M.; Yamato, M.; Kikuchi, A.; Okano, T. Cell Migration Assay Using Multiple Laminar Flows in PDMS Microchannel. In Proceedings of the International Symposium on Micro-NanoMechatronics and Human Science MHS '07, Nagoya, Japan, 11-14 November 2007; pp. 406-409.

36. O’Neill, A.T.; Monteiro-Riviere, N.; Walker, G.M. A serial dilution microfluidic device for cytotoxicity assays. Conf. Proc. IEEE Eng. Med. Biol. Soc. 2006, 1, 2836-2839.

37. Park, J.W.; Vahidi, B.; Taylor, A.M.; Rhee, S.W.; Jeon, N.L. Microfluidic culture platform for neuroscience research. Nat. Protoc. 2006, 1, 2128-2136.

38. Saadi, W.; Wang, S.; Lin, F.; Jeon, N.L. A parallel-gradient microfluidic chamber for quantitative analysis of breast cancer cell chemotaxis. Biomed. Microdevices 2006, 8, 109-118.

39. Saadi, W.; Rhee, S.W.; Lin, F.; Vahidi, B.; Chung, B.G.; Jeon, N.L. Generation of stable concentration gradients in 2D and 3D environments using a microfluidic ladder chamber. Biomed. Microdevices 2007, 9, 627-635.

40. Sia, S.K.; Whitesides, G.M. Microfluidic devices fabricated in poly(Dimethylsiloxane) for biological studies. Electrophoresis 2003, 24, 3563-3576.

41. Situma, C.; Hashimoto, M.; Soper, S.A. Merging microfluidics with microarray-based bioassays. Biomol. Eng. 2006, 23, 213-231.

42. Snyder, J.D.; Desai, T.A. Microscale three-dimensional polymeric platforms for in vitro cell culture systems. J. Biomater. Sci. Polym. Ed. 2001, 12, 921-932.

43. Taylor, A.M.; Rhee, S.W.; Jeon, N.L. Microfluidic chambers for cell migration and neuroscience research. Methods Mol. Biol. 2006, 321, 167-177. 
44. Walker, G.M.; Monteiro-Riviere, N.; Rouse, J.; O’Neill, A.T. A linear dilution microfluidic device for cytotoxicity assays. Lab Chip 2007, 7, 226-232.

45. Li Jeon, N.; Baskaran, H.; Dertinger, S.K.; Whitesides, G.M.; van de Water, L.; Toner, M. Neutrophil chemotaxis in linear and complex gradients of interleukin-8 formed in a microfabricated device. Nat. Biotechnol. 2002, 20, 826-830.

46. Lin, F.; Nguyen, C.M.; Wang, S.; Saadi, W.; Gross, S.P.; Jeon, N.L. Neutrophil migration in opposing chemoattractant gradients using microfluidic chemotaxis devices. Ann. Biomed. Eng. 2005, 33, 475-482.

47. Irimia, D.; Toner, M. Spontaneous migration of cancer cells under conditions of mechanical confinement. Integr. Biol. 2009, 1, 506-512.

48. Rao, S.M.N.; Lin, V.K.; Tata, U.; Raj, G.V.; Hsieh, J.-T.; Nguyen, K.; Chiao, J.-C. Demonstration of cancer cell migration using a novel microfluidic device. J. Nanotechnol. Eng. Med. 2010, 1, doi:10.1115/1.4001280.

49. Tata, U.; Rao, S.M.N.; Sharma, A.; Pabba, K.; Pokhrel, K.; Adhikari, B.; Lin, V.K.; Chiao, J.C. Study of lung-metastasized prostate cancer cell line chemotaxis to epidermal growth factor with a BIOMEMS device. Adv. Nat. Sci. Nanosci. Nanotechnol. 2012, 3, doi:10.1088/2043-6262/3/3/035007.

50. Bretscher, M.S. Getting membrane flow and the cytoskeleton to cooperate in moving cells. Cell 1996, 87, 601-606.

51. Iijima, M.; Huang, Y.E.; Devreotes, P. Temporal and spatial regulation of chemotaxis. Dev. Cell 2002, 3, 469-478.

52. Charest, P.G.; Firtel, R.A. Feedback signaling controls leading-edge formation during chemotaxis. Curr. Opin. Genet. Dev. 2006, 16, 339-347.

53. Sasaki, A.T.; Firtel, R.A. Regulation of chemotaxis by the orchestrated activation of ras, PI3K, and TOR. Eur. J. Cell Biol. 2006, 85, 873-895.

54. Janetopoulos, C.; Firtel, R.A. Directional sensing during chemotaxis. FEBS Lett. 2008, 582, 2075-2085.

55. Steeg, P.S. Metastasis suppressors alter the signal transduction of cancer cells. Nat. Rev. Cancer 2003, 3, 55-63.

56. Stephens, L.; Milne, L.; Hawkins, P. Moving towards a better understanding of chemotaxis. Curr. Biol. 2008, 18, R485-R494.

57. Signal Transduction in Cancer Metastasis; Wu, W., Hu, C.H., Eds.; Springer: Dordrecht, The Netherlands, 2010.

58. Mak, M.; Reinhart-King, C.A.; Erickson, D. Microfabricated physical spatial gradients for investigating cell migration and invasion dynamics. PLoS One 2011, 6, doi:10.1371/journal.pone.0020825.

59. Harris, J.; Lee, H.; Vahidi, B.; Tu, C.; Cribbs, D.; Cotman, C.; Jeon, N.L. Non-plasma bonding of PDMS for inexpensive fabrication of microfluidic devices. J. Vis. Exp. 2007, 9, doi:10.3791/410.

60. Tata, U.; Rao, S.; Nguyen, K.; Lin, V.K.; Chiao, J.C. A Microfluidic Approach to Study the Effect of Growth Factors on PC3 Cell Migration. In Proceedings of the BMES Biomedical Engineering Society Annual Meeting 2011, Hartford, CT, USA, 12-15 October 2011. 
61. Kaighn, M.E.; Narayan, K.S.; Ohnuki, Y.; Lechner, J.F.; Jones, L.W. Establishment and characterization of a human prostatic carcinoma cell line (PC-3). Invest. Urol. 1979, 17, 16-23.

62. Cussenot, O.; Berthon, P.; Berger, R.; Mowszowicz, I.; Faille, A.; Hojman, F.; Teillac, P.; le Duc, A.; Calvo, F. Immortalization of human adult normal prostatic epithelial cells by liposomes containing large T-SV40 gene. J. Urol. 1991, 146, 881-886.

63. Han, J.; Lee, J.D.; Bibbs, L.; Ulevitch, R.J. A MAP kinase targeted by endotoxin and hyperosmolarity in mammalian cells. Science 1994, 265, 808-811.

64. Bohil, A.B.; Robertson, B.W.; Cheney, R.E. Myosin-X is a molecular motor that functions in filopodia formation. Proc. Natl. Acad. Sci. USA 2006, 103, 12411-12416.

(C) 2014 by the authors; licensee MDPI, Basel, Switzerland. This article is an open access article distributed under the terms and conditions of the Creative Commons Attribution license (http://creativecommons.org/licenses/by/3.0/). 